\title{
Ergenlerde Sanal Zorbalik Ve Mağduriyetin Empati İle İlişkisinin
} İncelenmesi

\section{Relationship Between Cyber Bully, Victim At Adolescents And Their Emphaty}

\section{DOI $=10.17556 /$ jef.66842}

\author{
Mücahit KAĞAN*, Alaattin CIMINLLI**
}

\section{Özet}

Çă̆ımızın en hızlı gelişim gösterdiği alanların başında internet ve bilgisayar gelmektedir. Bu gelişim internet ve bilgisayara farklı işlevler yüklemektedir. Teknolojinin baş döndürücü gelişimi insan hayatını daha yaşanabilir seviyelere çıkarmasının yanında çeşitli olumsuzlukları da beraberinde getirmiştir.

Teknolojik değişimlerle gelişmekte olan dünyada iletişim teknolojilerinin günlük yaşama girmesi insanların yaşantılarını değaiştirmektedir.Gündelik yaşamda insanların sıklıkla başvurduğu internet ve iletişim araçları kullanım süreleri aşıldığında çeşitli sorunlar ortaya çıkarmaktadır.İnsanların bir kısmı interneti ve diğer iletişim araçlarını sadece gerektiğinde kullanırken diğer bir kısmı ise eğlenmek ve zaman geçirmek için kullanmaktadırlar.Bu aşırı kullanım kişinin birçok olumsuzlukla karşılaşmasına neden olmaktadır.

$\mathrm{Bu}$ bağlamda zorbalık olayına bir şekilde dahil olabilecek öğrencilerin öğretmenler tarafından önceden tespit edilebilmesi onların empati düzeylerinin bilinmesiyle mümkün olacaktır.

Araştırma Erzincan İlinde bulunan beş farklı ortaöğretim kurumunda öğrenim görmekte olan beş yüz kırk dört öğrenci üzerinde gerçekleşmiştir. Veri toplama aracı olarak Kişisel Bilgi Formu, Sanal Zorbalık Ölçeği, Sanal Mağduriyet Ölçeği ve Temel Empati Ölçeği kullanılmıştır. Araştırma empatinin sanal zorbalık ve sanal mağduriyet üzerinde etkili olduğunu ortaya koymuştur. Empati puanları sanal zorbalık ve mağduriyet puanlarını negatif bir etkiyle yordamaktadır. Empati puan ortalamaları arttıkça sanal zorbalık ve sanal mağduriyet puan ortalamaları düşmektedir.

Anahtar Sözcük:sanal zorbalık, mağduriyet, empati, ergen

\section{Abstract}

In our era, Internet and computers are the most rapidly evolving fields. This evolution puts different functions on Internet and computers. Vertiginous evolution

* Doç. Dr. Erzincan Üniversitesi Eğitim Fak. PDR

** Milli Eğitim (Rehber Öğretmen) 
of Technology brought betterment of human life to more livable levels with various negativities.

In the world developing with technological changes, entry of communication technologies to daily life changes humans' lives. Internet and communication devices which humans use frequently in daily life causes various problems when overused. Some humans use Internet and other communication devices only when needed other humans use them for pleasure and spending time. This excessive usage causes the person encounter a lot of negativities.

In this context detection of students whom may somehow involve in an event of bullying beforehand by teachers shall be possible by knowing their empathy levels.

The research, which is about five different secondary schools in Erzincan, have materialized on 544 students. As a data collection device, Personal İnformation Form, Cyber Bully Questionnaire, Cyber Victim Questionnaire and Basic Empahty Scale have been used in this device.

The research put forward the effect of empahty on cyber bullying and cyber victim. When the empahty mean increases, cyber bullying and cyber victim decrease.

Keywords: cyber bullying, victim, empathy, teenager

\section{Giriş}

Zorbalığın iletişim araçları ve teknolojiyle bütünleşmesi sonucu yeni bir boyutu daha ortaya çıkmıştır. Bilgisayar, internet ve cep telefonunu kişisel kullanımının artması bu tür teknolojilerin eğitim öğretim sürecinde kullanılması teknolojiyi ergenler için vazgeçilmez bir unsur haline getirmiştir(Arıcak, 2011).Bu nedenle zorbalık davranışı da zamandan ve mekândan bağımsız olarak gerçekleştirilebilen bir hal almıştır.

Teknolojinin bu denli önemli olduğu bir dönemde internet üzerinden yapılan tehdit edici, zorbalık içeren davranışlar okul çağında olan bireylerde ciddi sorun alanları ortaya çıkarmaktadır.

$\mathrm{Bu}$ nedenlesanalzorbalık, belli önyargılara saplanıp kalınarak, yaygın bazı inanış ve düşüncelerle değerlendirilerek ya da olayın varlığının inkârı ile ortadan kaldırılabilecek bir sorun değildir.Sanalzorbalık, birçok durumda ciddi psikolojik problemlere neden 
olduğu için özellikle çocukluk ve ergenlik döneminde üzerinde hassasiyetle durulması gereken bir konudur(Arıcak, 2011).

Ergenlik çağını birçok psikolog yeniden doğuş çağı, çocukluktan yetişkinliğe geçiş için gereken önemli gelişim görevlerini başarma çağı, bireyin bağımsızlık savaşı verdiği çağ, zorlanmalı yaşam dönemlerinden ilki olarak görmektedir (Kılıççı, 2000).Bu sancılı dönemdeki ergen sanal ortam sayesinde dünyanın farklı bölgelerinden bile arkadaş edinmektedir. Fakat ergen sanal ortamdan gelecek tehditleri gerçek yaşamdaki kadar önemsememektedir. Bu nedenle gerçek arkadaş grubunu oluşturduğu zaman gösterdiği hassasiyeti sanal arkadaş grubunu oluştururken göstermemektedir. $\mathrm{Bu}$ nedenle çeşitli türdeki zorba davranışlara maruz kalmaktadır.Bu tür zorba davranışlar öğrencilerin psiko-sosyal gelişimlerini olumsuz olarak etkilediği gibi ileriki dönemlerde de istenmeyen davranışların ortaya çıkmasına neden olabilir.

\section{Sanal Zorbalı̆̆ın Tanımı}

Ülkemizde internet, cep telefonu ve bilgisayar kullanımı gençler arasında hızla yaygınlaşmış.Gençlerin arkadaş edinme ve sosyal ilişkilerin düzenlenmesinde önemli bir araç haline gelmiştir (Eroğlu ve Peker, 2011).Ayrıca internet, bilgisayar ve cep telefonu gibi iletişim araçları birçok insana bilgiye hızlı bir şekilde ulaşabilme, duygu ve düşüncelerini rahatça ifade edebilme ve sosyal ilişkiler kurabilme olanağı sunmaktadır (Yaman, Eroğlu ve Peker, 2011).Teknolojinin bu avantajlarının yanı sıra dezavantajları da mevcuttur. Özellikle teknolojiyle iç içe olan gençlerin olumsuz olarak etkilendiği sanal zorbalık olgusu sadece ülkemizde değil tüm dünyada etkileri araştırılan ve üzerine çalışmalar yapılan bir hal almıştır. $\mathrm{Bu}$ bağlamda aşağıda sanal zorbalığın yurt içinde ve yurt dışında yapılan tanımlamalarına yer verilecektir.

Belsey (2004) sanalzorbalığı genel olarak, bilgi ve iletişim teknolojileri aracılığıyla bir kişi veya grup tarafından başkalarına zarar vermek için yapılan kasıtlı, tekrarlanan ve saldırgan davranışları içeren zorbalık türü olarak tanımlanmıştır. 
Sanal zorbalığı; web siteleri, anlık mesajlaşma, bloglar, sohbet (chat) odaları, cep telefonları, elektronik posta gibi elektronik araçlar vasitasıyla diğer bireylerin tehdit edilmesi, küçük düşürülmesi veya onlara cinsel objeler içeren resim ve mesajların gönderilmesi olarak tanımlamak da mümkündür (Shariff,2008).

Slonje ve Smith (2008) sanal zorbalığı; "geleneksel zorbalığın SMS, elektronik posta, cep telefonu kameraları ve internet aracılığıyla yapılması" olarak tanımlamıştır. Bu tanım sanal zorbalığın geleneksel zorbalığın bir türü ve devamı olarak görüldüğünün bir kanitidir.

Sanal zorbalığı bilgisayar, cep telefonu ve diğer elektronik araçların ısrarlı ve tekrar edici bir şekilde başkalarına zarar vermek amacıyla kullanılması olarak tanımlayan Hinduja ve Patchin (2010) bir davranışın sanal zorbalık olarak değerlendirilebilmesi için "1srar edicilik, tekrar etme ve zarar verme ölçütlerini sağlaması gerektiğini ifade etmiştir.

Teknolojik gelişmelerin bir sonucu olarak geleneksel zorbalığın farklı bir türü olarak ortaya çıkan sanal zorbalık; bilgi ve iletişim teknolojilerini kullanarak bir birey ya da gruba, özel ya da tüzel bir kişiliğe karşı yapılan teknik ya da ilişkisel tarzda zarar verme davranışlarının tümü olarak tanımlanmaktadır (Arıcak, 2011; Eroğlu ve Peker, 2011).

Sanal zorbalık alanında çalışan her araştırmacı sanal zorbalığı farklı şekillerde tanımlamışlardır.Fakat her tanımda araştırmacıların üzerinde durduğu ortak payda sanal zorbalık davranışının bir teknolojik araçla yapılması ve karşıdaki kişiye kasıtlı olarak zarar verme amacı gütmesidir. Sanal zorbalığın teknolojik bir araçla yapılması sanal zorbalığı geleneksel zorbalıktan ayıran en önemli özelliktir (Hinduja ve Patchin, 2010).Ayrıca kasıt gözetmeksizin yapılan hiçbir davranış zorbalık olarak nitelendirilemez. Bu yüzden sanal zorbalık davranışının da kasıtlı olarak gerçekleştirilmesi gerekmektedir ( Belsey, 2004) . Bu bağlamda ( Topçu ve diğerleri, 2008) sanal zorbalık olarak nitelendirilen davranışları şu şekilde örneklendirmişlerdir. 
a)Bir kişinin uygunsuz görüntülerini çekme

b)Cep telefonu veya e-posta yoluyla cinsel içerikli, tehditkâr, alay edici mesajlar gönderme

c) Başka bir kişiye sanal ortamda iftira atma

d)Bir kişiyi hiçbir gerekçesi olmadan sanal gruptan atma olarak gösterilebilir.

\section{Sanal Zorbalığın Görülme Biçimleri}

Sanal zorbalık da geleneksel zorbalık davranışı gibi farklı şekillerde ortaya çıkabilir. İnternet ve diğer iletişim araçlarının kişiye oluşturmuş olduğu sanal dünyada kişinin fiziksel zorbalığa maruz kalması pek mümkün değildir. Bu tür ortamlarda yaşanan zorbalık türlerinin daha çok sözel alanda gerçekleşmesi beklenir. Bu bağlamda sanal dünyada yaşanan zorbalık türlerine aşağıda değinilecektir.

Online Kavga: Genel olarak herkesin görebildiği sanal sohbet ortamlarında saldırganca ve kaba söylemlerin kullanıldığı tehdit içerikli davranışlardır. Saldırganca ve kaba davranışların her iki tarafta da mevcut olması online kavgayı tacizden ayırmaktadır (Willard, 2005; 2007).

Sanal Taciz: Çoğunlukla mesaj veya e-posta yoluyla bir başkasına sürekli olarak tehdit içeren mesajlar atma şeklinde meydana gelmektedir. Genellikle bir birlikteliğin sonlanmasının akabinde gerçekleşir. Sanal taciz, atılan mesajın süreklilik arz etmesi, tehditkâr bir içeriğe sahip olması ve aşırı derecede saldırganlık içermesi yönünden diğer mesajlaşmalardan ayrılır (Baker, 2010; Willard, 2005; 2007).

İftira: Bir kişinin başka bir kişi hakkında gerçeği yansıtmayan bilgileri, tahrif edilmiş görüntüleri herkesin kolaylıkla ulaşabileceği sosyal paylaşım sitelerinde paylaşması anlamına gelmektedir. Bu davranışı yapan kişiler bu bilgi ve görüntüleri bir başkasının silemeyeceği formatta paylaşırlar ve bu şekilde mağdur kendi adı kullanılarak paylaşılan bilgi ve görüntüleri görse dahi silememektedir.İftiranın farklı bir boyutu olan dijital görüntülerin tahrif edilerek yayınlanması çoğunlukla gerçek dünyada karşıdaki kişiden zarar gördüğü halde 
karşı1ık verememiş bu hırsını sanal ortamda intikam duygusuna dönüştüren bireyler tarafindan kullanılmaktadır (Willard, 2005; 2007).

Taklit: Kişinin çeşitli yöntemleri kullanarak başka bir kişi olarak davranması olarak tanımlanabilir. Bu yöntemle kişi tehdit edilebilir veya sosyal arkadaşlık ortamında itibarını sarsacak, onu küçük düşürecek paylaşımlarda bulunulabilir. Bilginin kimin tarafından paylaşıldığının belli olmadığ1 ve bilginin doğruluğunun şüpheli olduğu sanal ortam kötü niyetli kişilere kimliğini gizleyerek başkaları adına paylaşımlarda bulunma imkânı sağlamaktadır. Bu tür kişiler başkalarının şifrelerini ve hesap girişlerini ele geçirmek suretiyle başkaları adına onları zora sokacak davranışlarda bulunabilirler (Patchin ve Hinduja, 2006; Willard, 2007; Baker, 2010).

Sanal Ortamda İzinsiz Olarak Bilgi ve Görüntü Paylaşımı: Kişinin, kimsenin görmek istemediği, mahrem bilgi veya görüntülerini herkesin ulaşabileceği sitelere gönderme ve bu sitelerde paylaşma şeklinde meydana gelebilir. Özellikle ayrılmış çiftler karşı tarafi karalama amaciyla bu bilgi ve görüntüleri paylaşabilmektedir.Çoğunlukla karşı tarafa bir şey yaptırılmak istendiğinde şantaj malzemesi olarak kullanılır. Ayrıca bu zorbalık türü kişinin sadece bir kişiyle paylaşması daha sonrasında bilgi ve görüntünün bu kişi vasıtasıyla yayılması şeklinde de olabilir (Baker, 2010; Willard, 2007).

Dışlama: Kişiyi dâhil olduğu sanal gruptan dışlama şeklinde tanımlanabilir. Sanal gruptan dişlamanın yanı sıra oyun sitelerinden, sosyal paylaşım sitelerinden ve sohbet gruplarından atma şeklinde de olabilir. Bu dişlama kısa süre olsa dahi dışlanmaya maruz kalan bireylerde ruh hallerinde bozulma ve özsaygı düşüklüğü gözlenmektedir ( Baker, 2010; Willard, 2005; 2007).

Sanal Tehdit: Kişinin kendisine veya bir başka kişiye zarar vereceğini belirten mesajlar iletişim araçları vasıtasıyla paylaşması olarak tanımlanmaktadır (Yaman, Eroğlu ve Peker, 2011).

Sanal Zorbalık Araçları 
Ergenlerde bilgisayar ve cep telefonlarının kullanımının artmasıyla sanal zorbalık davranışı daha yaygın bir hale gelmiştir. Sanal zorbalık davranışını gerçekleştiren bireyler birçok araç kullanmaktadırlar.Sanal zorbalık davranışında kullanılan araçları Rogers (2010) şu şekilde sınıflandırmışlardır.

Yazılı Mesajlar: Cep telefonu ve benzeri cihazlara yazılı mesajlar gönderilmesidir.

Yazılı mesajlar iki veya daha fazla mobil cihaz arasında gerçekleşen, tehdit içeren ve sürekli olarak devam eden bir durumdur. Tek kullanımlık ve kullandıkça öde tarifeli cihazların kullanımı mağdurun zorbasını bulmasını zorlaştırmaktadır ve mağdur zorbasının kimliğini hiçbir zaman öğrenememektedir.

Fotoğraf / Video Klibi: Cep telefonu veya fotoğraf makinesiyle hazırlanan fotoğraf ve videolardan meydana gelmektedir. Sanal zorbalıkta tehdit etmek, rahatsızlık ve utanmışlık hissi vermek amacıyla kullanılır ve bu resim ve videolar sosyal paylaşım sitelerinde paylaşılarak birçok kişiye ulaştırılabilir.

Telefon: Çok yaygın bir iletişim aracı olduğu için sanal zorbalık davranışını yapan bireyler tarafından sıkça kullanılır. Çoğunlukla sürekli arama, kötü amaçlı mesajlar atma ve kişinin telefonunu çalarak diğer kişileri bu telefondan taciz etme şeklinde kullanılır.

E-posta: İletişim ağları kullanılarak mesajların aktarımını sağlar. Zorbanın kendi kimliğini kullanma zorunluluğu olmaksızın başkasının kimlik bilgilerini kullanarak birden fazla e-posta alabilmesi yakalanma riskini azalttığı için zorbalar tarafından kullanılmaktadır.

Sohbet Odaları: Bir iletişim aracı vasıtasıyla iki kişi arasında eş zamanlı olarak gerçekleşen bir iletişimdir. Güvenlik önlemlerinin yetersiz oluşu nedeniyle zorba bireyler tarafından tehdit amaçlı kullanılabilen bir iletişim yöntemidir.

Sosyal Paylaşım Siteleri: $\mathrm{Bu}$ paylaşım siteleri yazı ve resim paylaşmak amacıyla kullanılır. Güvenlik önlemleri yetersiz olduğunda sanal zorbalar kendi kimliğini belli etmeksizin farklı hesaplar açıla- 
bilir. Gençler arasında popüler olma maksadıyla birçok kişi çok fazla arkadaşlık isteğini onaylayabilir. Bu durum zorbaların mağdurlarına daha kolay ulaşmalarını sağlayabilir.

Anında Mesajlaşma: Başka bir kişiyle özel bir sohbet odası oluşturmaya olanak sağlar. Kişinin özel listesindeki kişiler çevirim içi olduklarında kullanılır.

Web Siteleri: HTML (Hyper Text Markup Language) olarak bilinen bir işaretleme dili mevcuttur. Zorba kişiler mağdurları ile ilgili küçük düşürücü web siteleri oluşturabilirler $\mathrm{Bu}$ sitelere kolaylıkla ulaşılabilir.Özellikle ünlü kişiler ve politikacılar hakkında oylama siteleri oluşturularak oy kullanılması sağlanabilir.Bu durum kötü niyetli kişiler tarafından kullanıldığında oylama sonuçları kişiyi olumsuz olarak etkileyebilir.

Araştırmanın genel amacı; ergenlerde empati düzeyinin sanal zorbalık ve sanal mağduriyet ile ilişkisinin incelenmesidir.Bu genel amaç doğrultusunda aşağıdaki sorulara cevap aranacaktır.

\section{Alt Problemler}

1-Sanal zorbalık puanları empatinin anlamlı bir yordayıcısı midır?

2- Sanal mağduriyet puanları empatinin anlamlı bir yordayıcısı mıdır?

\section{Yöntem}

\section{Araştırmanın Deseni}

Tarama modelleri, bir durumu olduğu gibi araştırıp açıklamayı hedefleyen araştırma yaklaşımlarıdır(Karasar, 2009).Bu araştırmada ilişkisel tarama yöntemi kullanılmıştır. Araştırma Erzincan il merkezinde öğrenim görmekte olan ortaöğretim öğrencileri üzerinde gerçekleştirilmiştir. Betimsel araştırmalar, "bir konunun hali hazırdaki durumunu saptamayı hedeflemektedir" (Karasar, 2009).Illişkisel tarama ise, "iki ya da daha çok sayıdaki değişken arasında birlikte değişim 
varlığını ve/ya da derecesini belirlemeyi amaçlayan araştırma modelleridir" (Karasar, 2009).

\section{Çalışma Grubu}

$\mathrm{Bu}$ araştırmanın evrenini; 2015 - 2016 eğitim - öğretim yılında Erzincan/Merkez de bulunan resmi ortaöğretim kurumlarının 9.,10.,11. ve 12., sınıfında öğrenim görmekte olan öğrencileri kapsamaktadir.

$\mathrm{Bu}$ araştırmanın örneklemi Tabakalı Örnekleme Yöntemi olarak belirlenmiştir. Tabakalı Örnekleme Yöntemi, evrendeki alt grupların belirlenip bunların evrende var oldukları aynı oranlarıyla örneklerinde temsil edilmelerini sağlayan bir örneklem seçme tekniğidir.Araştırmanın amacı bakımından evrendeki her bir tabakanın yüzdeliğinegöre örnekleme yansımasının önemli olup, olmayışına göre tabakalardanörnek seçme işlemi oranlı ya da oransız olmak üzere iki şekilde yapılabilir.Oransız tabakalı örneklem, tabakaların evrendekioranına bakılmaksızın, her tabakaya eşit sayıda eleman alınır(Karasar, 2009).

Kullanılan örnekleme yöntemiyle farklı türdeki beş ortaöğretim kurumu örnekleme alınmıştır. Çalışmada örnekleme dâhil edilen liseler: Fen Lisesi, Sosyal Bilimler Lisesi, Anadolu Lisesi, Anadolu İmam Hatip Lisesi (A İHL) ve Mesleki ve Teknik Anadolu Lisesi (MTAL) olarak belirlenmiştir. Örnekleme alınan okulların 9.10.,11. ve 12. siniflarından birer küme bu örnekleme yöntemi ile seçilmiştir. Örnekleme dâhil edilen toplam öğrenci sayısı beş yüz kırk dörttür.Fakat araştırmada elli beş öğrencinin cevaplamaları geçersiz sayıldığından örneklem grubundan çıkarılmış ve araştırma dört yüz seksen dokuz öğrenci üzerinden gerçekleştirilmiştir. 
Tablo:1Öğrenci Sayılarının Okul Türlerine Ve Sınıf Düzeylerine Göre Dağılımı

\begin{tabular}{llllcc}
\hline Okul Türü & 9. Sinıf & 10.Sınıf & 11.Sınıf & 12.Sınıf & Toplam \\
\hline Fen Lisesi & 26 & 26 & 25 & 28 & 105 \\
Sosyal Bil. Lisesi & 28 & $0^{*}$ & 37 & 23 & 88 \\
Anadolu Lisesi & 24 & 24 & 28 & 25 & 101 \\
AİHL & 25 & 23 & 24 & 27 & 99 \\
MTAL & 27 & 25 & 21 & 23 & 96 \\
Toplam & 130 & 99 & 134 & 126 & 489 \\
\hline
\end{tabular}

*:Anadolu Öğretmen Liselerinden dönüşen Sosyal Bilimler Lisesine hazırlık sınıfı eklendiği için onuncu sınıf düzeyinde öğrenci bulunmamaktadir.

Tablo:2Öğrenci Sayılarının Cinsiyete Göre Dağılımı

\begin{tabular}{lcl}
\hline Cinsiyet & $\%$ & N \\
\hline Erkek & 46,10 & 225 \\
K1z & 53,90 & 264 \\
Toplam & 100,0 & 489 \\
\hline
\end{tabular}

\section{Bulgular}

1.Sanal zorbalık ve sanal mağduriyetin empatiyi yordamasına ilişkin sonuçlar Tablo 3' te verilmiştir.

Tablo:3Empati Verilerinin Bağımlı Değişken; Sanal Zorbalık(SZ) Ve Sanal Mağduriyet(SM) Değişkenlerinin Yordayıcı Değişken Olarak Alındığ $\breve{1}_{\text {Regresyon Analizi }}$

\begin{tabular}{lccccccc}
\hline & B & S.H. & B & t & p & İkili r & K1s. r \\
\hline Sabit & 108,85 & 6,05 & & 17,97 &, 00 & & \\
Sanal Zorbalık &,- 668 &, 11 &,- 322 & $-6,01$ &, 00 &,- 393 &,- 095 \\
SanalMağduriyet &,- 574 &, 27 &,- 113 & $-2,11$ &, 00 &,- 316 &,- 263 \\
& & & & & & & \\
\hline
\end{tabular}


Tabloda yer alan analiz sonuçlarında öncelikle empati değişkeni ile sanal zorbalık ve sanal mağduriyet değişkenleri arasındaki ikili ve kısmi korelasyon sonuçları incelendiğinde empati ile sanal zorbalık arasında negatif ve orta bir ilişki olduğu $(r=, 393)$, diğer değişkenler kontrol edildiğinde iki değişken arasındaki kısmi korelasyon da negatif ve düşük düzeyde bir ilişki $(r=, 095)$ olarak hesaplandığı görülmektedir.

Sanal zorbalık ve sanal mağduriyet değişkenleri birlikte ele alındığında empati ile pozitif ve orta düzeyde anlamlı bir ilişkinin $(\mathrm{R}=, 402, \mathrm{p}<.001)$ ortaya çıktığ ${ }_{1}$ görülmektedir. Söz konusu değişkenler birlikte sanal zorba olma puanlarındaki değişimin \%16 'sını açıklamaktadır. Standartlaştırılmış regresyon katsayılarına göre, yordayıcı değişkenlerin empati üzerindeki göreli önem sırası, sanal zorbalık $(\beta=-, 32)$, sanal mağduriyet $(\beta=-, 11)$, olduğu görülmektedir.

Tablodaki bulgular incelendiğinde empati ile sanal zorbalık arasında negatif yönlü bir ilişki söz konusudur.Sanal zorbalık arttıkça empati düzeyi düşmektedir. Diğer bir deyişle sanal zorbalık boyutunda yüksek puan alan kimselerin daha az empatik eğilimleri olacaktır.

\section{Sonuç ve Tartışma}

1-) Yapılan araştırmaya göre empati ile sanal zorbalık arasında negatif yönlü bir ilişki söz konusudur.Buna göre sanal zorbalık arttıkça empati düzeyi düşmektedir. Diğer bir deyişle sanal zorbalık boyutunda yüksek puan alan kimselerin daha az empatik eğilimleri vardır. Konuyla alakalı literatür incelendiğinde benzer çalışmalara rastlanmıştır (Kowalski ve Limber, 2007; Ireland,1999; Joliffe ve Farrington,2006; Topcu,2008; Dilmaç,2009). 
Buna karşın empati puanlarının farklı zorbalık statülerine göre anlamlı bir farklılık göstermediğine ilişkin araştırma bulguları da mevcuttur (Gökler,2007; Pelencioğlu,2011).

Kendini bir başkasının yerine koyabilme (Dökmen,1988) olarak tanımlanan empati bireylerin birbirlerini daha iyi anlamalarını ve iletişim kurmalarını sağlar.Empati düzeyi yüksek olan bireylerin karşısındaki kişiye zarar vermesi beklenmez.Çünkü kendisi de mağdur durumuna düştüğünde nasıl bir ruh hali içerisinde olacağını düşünecektir.Zorbalığın yapıldığı ortam sanal olduğu için zorba kişi yaptığ1 davranışların mağdurda yol açtığı negatif etkileri görememekte ve mağdurla empati kuramamaktadır.Dolayısıyla zorba sanal ortamdagerçekleştirdiği davranışın sadece sanal ortamda kaldığını düşünecek ve zorbalık davranışını bitirmede güçlük çekecektir.(Kowalski ve Limber, 2007).

Empatik olarak kendini geliştirmiş olan bireylerin kişiler arası ilişkileri başarılı,bu alanda kendini geliştirmemiş bireylerin kişiler aras1 iletişimleri ise başarısızdır(Pişkin,1991).Bu bağlamda empatik eğilimi yüksek kişilerin, kişiler arası iletişim kurmada çaba göstermeleri sanal zorbalığa bir şekilde dahil olmalarının önüne geçecektir(Peker ve diğ, 2012).Ayrıca Dilmaç(2009)'ın kişsel arkadaşlık kurma ve sürdürmeyi içeren yakınlığın sanal zorbalığı negatif yönde etkilediğini bulguladığı araştırma bu görüşü destekler niteliktedir.

Campfield(2008) ise arkadaşı az olan ve arkadaş ilişkilerinden memnun olmayan daha fazla sanal zorbalığa maruz kaldığını belirtmiştir.

\section{Öneriler}

1-Bu çalışma Erzincan il merkezinde öğrenim gören lise öğrencileriyle sinırlı tutulmuştur.Bundan sonra yapılacak olan çalışmalarda çalışma grubu daha kapsamlı olabilir ve ilköğretim ve yüksek öğretim gibi farklı eğitim seviyesindeki öğrenciler de çalışmaya dahil edilebilir.

2- Bu çalışmada empati ile sadece sanal zorba olanlar ve sanal mağdur olanlar incelenmiştir. Bundan sonra yapılacak çalışmalarda bu de- 
ğişkenlerle sanal zorbalığa ve mağduriyete seyirci kalanlar ve taraftar olanlar da araştırılabilir.

3-Bu çalışmada sanal zorbalık ve sanal mağduriyetle sadece empati değişkeni ele alınmıştır.Bundan sonra yapılacak araştırmalarda sanal zorbalık ve mağduriyet ile birlikte daha farklı değişkenler incelenebilir.

\section{Kaynaklar}

Arıcak, O. T.(2011) "Sanal Zorbalık: Gençlerimizi Bekleyen Yeni Bir

Tehlike", Kariyer Penceresi, www.kariyerpenceresi.com, S.2, 10-12.

Belsey, B.(2004) “Cyberbullying”, Http://Www.Cyberbully.Ca,(13.11.2015).

Campfield,D.C.(2008)Cyberbullying and victimization psychosocial characteristics of bullyies,victims and bully/victim,Unpublished doctoral dissertation, The Universty of Montana.

Dilmaç,B.(2009)Sanal zorbalığı yordayan psikolojik ihtiyaçlar,Lisans ögrencikeri için ön çalışma,,Kuram ve Uygulamada Eğitim Bilimleri,9(3),1291-1325.

Erdur-Baker, Ö.(2010) Cyberbullying And İts Correlation To Traditional Bullying, Gender, And Frequent And Risky Usage Of İnternet-Mediated Communication Tools. New Media Society, C. 12, S. 1, 109-125.

Eroğlu,Y. ve Peker, A. (2011). Aileden ve Arkadaştan Alınan Sosyal Destek Ve Siber Mağduriyet: Yapısal Eşitlik Modeliyle Bir İnceleme. Akademik Bakış.

Ireland,J.L.(1999).Provictims attitude andemphaty in relation to bulling behavior among prisoners,Legal and Criminalogical Psychology,51-56.

Jolliffe,D. ve Farrington,D.P.(2006)Examining the relation ship between low emphaty and bullying,Aggressive Behavior,32(6)540-550.

Karasar, N. (2009) Bilimsel araştırma yöntemi, Ankara: Nobel Yayın Dağıtım.

Kılıççı Y.(2000) Okulda Ruh Sağlığg, Ankara: Anı Yayıncılık.

Kowalski, R; Limber, S. ve Agatston, P. W. (2008) Cyberbullying: Bullying In The Digital Age , New York: Blackwell Publishing.

Lenhart, A.(2007) Cyber Bullying And Online Teens, Amerikan Life Project.

Olweus, D.(1993)Bullying At School, What We Know And What We

Can Do,Ma: Blackwell, Cambridge.

Patchin, J. ve Hinduja, S.(2006) Bullies Move Beyond The Schoolyard,

A Preliminary Look At Cyberbullying. Youth Violence And Juvenile Justice, C. 4 , S. 2.

Patchin, J. ve Hinduja, S.(2010) Cyberbullying And Selfesteem. Journal Of School Health, C. 80, S. 12, 614-621.

Peker,A.;Eroğlu Y. ve Ada,Ş(2012) Ergenlerde siber zorbalığın ve mağduriyetinyordayıcılarının incelenmesi,Abant BaysalUniversitesi Eğitim Fakültesi Dergisi,21(2). 
M.Kă̆an, A.Ciminli / EÜ Ĕ̆gitim Fakültesi Dergisi, 18-2(2016), 1135-1150

Pişkin,M.(1991)Empati kaygı ve çatışma eğilimi arasındaki ilişki,Ankara Üniversitesi Ĕ̈itim Fakültesi Dergisi,22(2),775-784.

Raskauskas, J. ve Stoltz, D.(2007) Involvement İn Traditional

And Electronic Bullying Among Adolescent, Developmental Psychology, C. 43, S. 3.

Rogers, V.( 2010) Cyberbullying: Activities To Help Children And Teens To Stay Safe İn A Texting, Twittering, Social Networking World, London.

Shariff, S.(2005) Cyber-Dilemmas In The New Millennium: School Obligations To Provide Student Safety İn A Virtual School Environment.Mc Gill Journal Of Education, S.467-487.

Slonje, R. ve Smith, P.( 2008) Cyberbullying: Another Main Type Of Bullying?Scandinavian Journal Of Psychology, S. 49, 147-154.

Suler, J.(2002)“Conflicts İn Cyberspace: How To Resolve Conflict Online", Http://Users.Rider.Edu/ Suler/Psycyber/Therintro.Html, (27.11.2015).

Topçu,Ç.(2008)The relationship of cyberbullying to emphaty ,gender, traditional bullying, internet use and adult monitoring,Unpublished Master Dissertation,Middle east Technical Unıversty,Ankara.

Topçu, Ç; Erdur Baker, Ö. ve Çapa-Aydın, Y.(2010)"Temel Empati Ölçeği Türkçe Uyarlaması: Geçerlik Ve Güvenirlik Çalışması," Türk Psikolojik Danışma Ve Rehberlik Dergisi.

Willard, N.(2005) Cyberbullying And Cyber Threats, Us Department Of Education Osdf National Conference, Washington.

Willard, N.(2007) Cyberbullying And Cyber Threats, Responding To The Challenge

Of Online Social Aggression, Threats, And Distress. Research Press.

Yaman, E. Eroğlu, Y. ve Peker, A.(2011); Okul Zorbalı̆̆ Ve Sanal Zorbalık, İstanbul : Kaknüs Yayınları.

Ybarra, M. ve Mitchell, K.(2004) Youth Engage İn Online Harassment: Associations With Caregiver-Child Relationships, İnternet Use, And Personal Characteristics. Journal Of Adolescence, C. 27, S. 3, $319-336$ 


\section{Extended Summary}

\section{Purpose}

The aim of this study is to the examinate the relationship between cyber bullying, and victimization at adolescents and their emphaty. For this purpose the questions that need to be answered are:

1- Is cyber bullying points predictors of empathy?

2- Is cyber victimization points predictors of empathy?

\section{Method}

Relational survey method is used in this study. The researc is condukted on high school students in Erzincan Center.The research, which is about five different high schools in Erzincan, have materialized on 544 students. As a data collection device, Personal İnformation Form, Cyber Bully Questionnaire, Cyber Victim Questionnaire and Basic Empahty Scale have been used in this device.

\section{Research Universe}

The research universe of this study consists of all students who are ongoing their education in high school grade in 2015 -2016 academic year in Erzincan Center.

\section{Research Sample}

The sample of this study is defined as the stratified sampling method. The research, which is about five different high schools with the sampling method used in Erzincan. At research, schools that were included in the sample: Science High School, Scial Science High School, Anatolian High School,Anatolian İmam Hatip High School, Vocational And Technical High School.

A set from each classes that including 9,10,11,12 th grade were selected by sampling. The research group of this study consists of 544 students but 55 stu- 
M.Kă̆an, A.Ciminli / Ë̈ Ĕ̆itim Fakültesi Dergisi, 18-2(2016), 1135-1150

dents answers were invalid and the sample group were excluded so the research was realized with 489 students.

\section{Results}

The research put forward the effect of empahty on cyber bullying and cyber victimization.there is a negative corralation between adolescents cyberbulling and emphatyWhen examining the literature relevant to the topic, A similar study was found (Kowalski ve Limber, 2007). Despite the fact that other research shows that a relationship between empathy and cyber bullying are not available (Gökler,2007; Pelencioğlu,2011).

Emphaty is the ability to share someone else's feelings allows individuals to establish communication and understanding of each other.It is not expected Individuals with high levels of empathy damage to the other people (Kowalski ve Limber, 2007).

\section{Discussion}

When the results were analyzed when the cyber bullying decrease ,empahty mean increases, As a consequently people with high scores from cyberbullying size has less empathic tendencies.

\section{Conclusion}

According to the results of this study, it has made the following recommendations:

Empathic tendencies of cyberbully and cybervictim were investigated in this study. After this study a relationship between empathic tendencies and persons who witnessed and supported cyberbullying was invastigated. 